\title{
Effect of Relative Air Humidity on the Stomatal Functionality in Fully Developed Leaves
}

D. Fanourakis ${ }^{1,}$ a, N. Matkaris ${ }^{1}$, E. Heuvelink ${ }^{1}$ and S.M.P. Carvalho ${ }^{1,2}$

${ }^{1}$ Wageningen University, Department of Plant Sciences, Horticultural Supply Chains Group, PO Box 630, 6700 AP, Wageningen, The Netherlands

${ }^{2}$ Portuguese Catholic University, College of Biotechnology, Rua Dr. António Bernardino de Almeida, 4200-072 Porto, Portugal

Keywords: adaptation dynamics, desiccation, Rosa hybrida, transpiration rate

\begin{abstract}
Several studies have shown that stomata developed under long-term high relative air humidity ( $\mathrm{RH} \geq \mathbf{8 5 \%}$ ) are malfunctional, resulting in a poor control of water loss. Yet, little is known about the dynamics of stomatal adaptation to moderate RH, and the possibilities to improve or reverse the destabilized stomatal responsiveness. In this study, a reciprocal transfer experiment was conducted in climate chambers using Rosa hybrida 'Prophyta', grown at moderate RH (60\%) or at high RH $(90 \%)$. The adaptation of fully developed leaves to the new RH environment was assessed at day $0,4,8$ and 12 after plant transfer by measuring the transpiration rate in detached leaves. Stomata fully developed at high RH had a lower closing capacity in response to a decrease in leaf Relative Water Content (RWC) (i.e. water loss was considerably high at RWC below $20 \%$, whereas in moderate RH stomata the water loss almost ceased at 57\% RWC). Furthermore, stomata developed at high $\mathrm{RH}$ did not become functional after 12 days of cultivation at moderate RH. Similarly, stomata developed at moderate RH and transferred to high RH for a 12 day period did not loose their ability to close in response to desiccation. This indicates that stomatal functionality is determined during leaf development, while after this period stomata have a limited capacity to adapt to new RH environment. It is concluded that stomata from fully developed rose leaves conserve their behaviour independently of the post-development humidity level.
\end{abstract}

\section{INTRODUCTION}

High relative air humidity levels $(\mathrm{RH}>85 \%)$ are common in greenhouses in Northern European Countries, especially during the winter (Mortensen and Gislerød, 2000), mainly due to low ventilation. As a result of the energy saving practices (e.g. temperature integration, thermal insulation; Körner and Challa, 2003) and new technologies (e.g. 'closed greenhouse' concept; Gelder et al., 2005), high RH is expected to occur even more frequently in protected cultivation. However, it is known that cut flowers grown under long-term high RH show a negative water balance during vase life, leading to poor keeping quality (Mortensen and Gislerød, 2005).

Stomata in leaves developed under long-term high $\mathrm{RH}$ have distinct anatomical and physiological characteristics, i.e. changed stomatal densities and stomatal dimensions, as well as less responsive stomata to closing treatments (Rezaei Nejad and Van Meeteren, 2008; Torre and Fjeld, 2001). Stomata malfunctioning has been recognized as a major cause of the uncontrolled water loss (water loss $>$ water uptake) during the postharvest phase in plants grown under high RH (Fanourakis et al., 2009; Torre and Fjeld, 2001). Nevertheless, little is known about stomatal adaptation dynamics when transferring plants from one RH level to another. Since exposure to a new RH environment after leaf development can induce physiological changes only, reciprocal experiments focusing on fully expanded leaves are powerful tools to separate the aforementioned effects of RH on stomatal characteristics and, therefore, to evaluate their importance on the control of water balance.

\footnotetext{
a Dimitrios.Fanourakis@wur.nl
} 
Stomatal adaptation in fully developed leaves to a new RH environment seems to be strongly species dependent. For instance, in Phaseolus vulgaris after seven days of transfer to high RH, stomata developed under moderate RH behaved the same as stomata which were continuously exposed to high RH. Similarly, plants grown under high RH completely restored their stomatal responses seven days after transfer to moderate $\mathrm{RH}$, thus reflecting a full stomatal adaptation to the new RH environment (Pospisilova, 1996). In Tradescantia virginiana, four days at high $\mathrm{RH}$ were enough to disrupt the stomatal functioning in leaves fully developed at moderate $\mathrm{RH}$, though this dysfunctionality was not reversible when plants were moved back to moderate $\mathrm{RH}$ during the further six days the experiment lasted (Rezaei Nejad and Van Meeteren, 2008). In contrast to Phaseolus and Tradescantia, it was reported in Rosa hybrida that plant transfer after leaf development to a RH level other than growth (i.e. moderate to high $\mathrm{RH}$, and vice versa) had no effect on stomatal behaviour. However, that conclusion was based on the analysis of only one rose cultivar and by assessing the stomatal responses to desiccation at day 0 (control) and at 21 days after plant transfer to the new RH environment (Mortensen and Gislerød, 2000; Mortensen and Fjeld, 1995).

Determining the possibility of restoring malfunctional stomata in rose cultivation after exposure to long-term high RH is highly important from both fundamental and practical point of view. Previous studies have shown that large cultivars differences in stomatal characteristics at high RH do exist (Fanourakis et al., 2009; Mortensen and Gislerød, 1999). This study aims at analysing the dynamics of stomatal adaptation to a new humidity environment in fully developed rose leaves, using a cultivar known to be very sensitive to high RH (Fanourakis et al., 2009) and focusing on stomatal functioning assessed at regular intervals (4 days) after plant transfer to a new RH environment.

\section{MATERIALS AND METHODS}

\section{Plant Material and Growth Conditions}

Rooted cuttings of cut rose cultivar 'Prophyta' were obtained from a commercial propagator (Kordes Roses, De Kwakel, The Netherlands), and planted in $3.6 \mathrm{~L}$ pots containing a mixture of cocopeat (Jongkind Grond B.V., Aalsmeer, The Netherlands) and perlite (Agraperlite nr. 3, Pull Rhenen, The Netherlands) $(3: 1, \mathrm{v} / \mathrm{v})$. This cultivar was selected due to its sensitivity to high RH (Fanourakis et al., 2009; Mortensen and Gislerød, 2005). Plants were grown in four growth chambers $(1 \times \mathrm{w} \times \mathrm{h}=1.3 \times 0.8 \times 1.3 \mathrm{~m})$ as single stem and at a density of 40 plants $\mathrm{m}^{-2}$. The RH was set at $60 \%$ in two chambers and at $90 \%$ in the other two, resulting in an average of $60 \pm 3 \%$ for moderate $\mathrm{RH}$ and $95 \pm 1 \%$ for high RH during the complete cultivation period. In all chambers a constant day/ night temperature of $19 \pm 1{ }^{\circ} \mathrm{C}$ was maintained, leading to a Vapour Pressure Deficit (VPD) of $0.90 \pm 0.07 \mathrm{kPa}$ for moderate $\mathrm{RH}$ and $0.21 \pm 0.07 \mathrm{kPa}$ for high $\mathrm{RH}$. The difference in the temperature and $\mathrm{RH}$ between the borders and the centre of the chambers was less than $5 \%$. These climate parameters were recorded automatically every five minutes using data loggers (Fourier MicroLog EC650, MicroDAQ.com, Ltd. Contoocook, USA). The $\mathrm{CO}_{2}$ concentration during the light period was $370 \pm 50 \mu \mathrm{mol} \mathrm{mol}^{-1}$ (Indoor Air Quality Meter Model 8760, TSI Incorporated, Shoreview MN, USA). Fluorescence tubes (Philips TLD $58 \mathrm{~W} / 84$, Eindhoven, The Netherlands) were on for 18 hours per day (from 07:00 to 01:00) providing $300 \pm 20 \mu \mathrm{mol} \mathrm{m}^{-2} \mathrm{~s}^{-1}$ photosynthetically active radiation (LI-COR Model LI-250, Nebraska, USA). The light intensity was measured at $70 \mathrm{~cm}$ from the pot base, which was just above the canopy of the full grown plants.

Plants were watered regularly with the following nutrient solution: major nutrients: $\mathrm{K}$ 4.0, $\mathrm{Ca} 3.5, \mathrm{Mg} 1.38, \mathrm{NO}_{3} 9.49, \mathrm{SO}_{4} 1.5, \mathrm{H}_{2} \mathrm{PO}_{4} 1.25(\mathrm{mM})$, and minor elements: Fe 25, Mn 5, Zn 3.5, B 20, Cu 0.75, Mo 0.5 ( $\mu \mathrm{M})$. Two different concentrations were used to water the plants $(1.5$ and $2 \mathrm{dS} / \mathrm{m})$ with a $\mathrm{pH}$ of 5.5 . Their use was dependent on the EC in the drain which was monitored daily (Inolab pH/Cond level 1 WTC, Sensor EC WTW TetraCon 325 and Sensor pH Electrode SenTix 61, Weilheim, Germany) and kept in the range of $1.5-2.5 \mathrm{dS} / \mathrm{m}$. 
At harvest stage [stage 2, after VBN (2001), i.e. loose pointed bud, with a cylindrical shape], half of the plants were transferred to the new humidity environment (i.e. $60 \% \rightarrow 90 \%$, and $90 \% \rightarrow 60 \% \mathrm{RH}$ ), while the other half were kept at the humidity level of growth and served as controls.

\section{Adaptation of Fully Developed Leaves to New RH Level}

To follow the time course of stomatal adaptation to the new RH environment, the transpiration rate in response to desiccation was recorded in fully developed leaves at day $0,4,8$ and 12 after the plant transfer - using 14 detached leaves per treatment (1 leaf/ plant). In the control plants $(60 \% \rightarrow 60 \% ; 90 \% \rightarrow 90 \%)$ these measurements were only conducted at harvest stage (day 0 ) and 12 days thereafter.

Terminal leaflets of the $1^{\text {st }}$ penta-foliate leaves (from the top of the plant) were detached, their petioles were re-cut under degassed water, and were placed in small flasks filled with water. These leaflets were further incubated in a saturated humidity environment ( $100 \% \mathrm{RH}, 21^{\circ} \mathrm{C}$; VPD close to 0$)$ for $1 \mathrm{~h}$ to establish their maximum fresh weight. The re-hydration process took place under light $\left(15 \mu \mathrm{mol} \mathrm{m}^{-2} \mathrm{~s}^{-1}\right)$, since following darkness light-induced stomatal opening requires up to $1 \mathrm{~h}$ in roses (Blom-Zandstra et al., 1995). Subsequently, the petioles were removed from water and the leaflets were placed in the test room $\left(50 \pm 3 \% \mathrm{RH}, 21^{\circ} \mathrm{C}, 1.47 \mathrm{kPa}\right.$ VPD and $\left.50 \mu \mathrm{mol} \mathrm{m} \mathrm{m}^{-2} \mathrm{~s}^{-1}\right)$, where their transpiration rate was measured gravimetrically for $3 \mathrm{~h}$. Then, leaf area was determined using a leaf area meter (LI-COR, model 3100 Area Meter, Lincoln NB, USA), and the leaves were dried at $80^{\circ} \mathrm{C}$ for $24 \mathrm{~h}$. The transpiration rate was calculated per unit leaf area, and per unit Relative Water Content (RWC) according to Slavik (1974) (Equation 1).

$$
R \mathrm{WC}=\frac{\text { Fresh Weight }- \text { Dry Weight }}{\text { Saturated Fresh Weight }- \text { Dry Weight }} * 100
$$

\section{RESULTS}

\section{Stomatal Responses to Desiccation}

Stomatal responses to leaf desiccation differed between leaves developed at moderate or high RH (Fig. 1). After a transient increase in the leaf transpiration rate for a period of $10 \mathrm{~min}$, the transpiration rate strongly decreased as leaves dehydrated. However, stomata developed at high RH were less responsive to desiccation, both in terms of speed and degree of closure, resulting in higher transpiration rates. The critical RWC, at which transpiration rate became stable and water loss almost ceased, was $57 \%$ in leaves grown at moderate $\mathrm{RH}$ after 150 min of leaf desiccation. In contrast, in leaves grown at high $\mathrm{RH}$ the transpiration rate did not stabilize and water loss was still quite high at RWC values below 20\% (Fig. 1B).

\section{Adaptation of Fully Developed Leaves to New RH Level}

Similarly to the control plants (i.e. continuously grown at $60 \%$ and at $90 \%$ ), in leaves fully developed at a given $\mathrm{RH}$ level and further transferred to a new $\mathrm{RH}$ environment (i.e. $60 \% \rightarrow 90 \%$, and $90 \% \rightarrow 60 \% \mathrm{RH}$ ) the transpiration rate was strongly decreased as leaves dehydrated (Fig. 2). Furthermore, when analysing the time course of stomatal adaptation it was found that independently of the leaf desiccation exposure time $(60,120$ and $180 \mathrm{~min})$ the transpiration rate was kept constant throughout the 12 days in the new RH environment (Fig. 2). Moreover, the leaf transpiration rates from the transferred plants were similar to the corresponding control plants. For instance, leaves fully developed at moderate $\mathrm{RH}$ and then transferred to high $\mathrm{RH}$ for a period up to 12 days, had the same transpiration rate as leaves continuously kept at moderate $\mathrm{RH}$. The same happened with leaves fully developed at high $\mathrm{RH}$ and transferred to moderate $\mathrm{RH}$, which showed a reduced ability to respond to desiccation in a similar way as leaves kept at high RH for the whole period (Fig. 2). These results reflect that there was no stomatal adaptation to the new RH environment after leaf development. 


\section{DISCUSSION}

It has been shown in several plant species that stomata closure in leaves grown under long-term high RH is less responsive to desiccation than in those grown at a moderate RH (Phaseolus vulgaris: Pospisilova, 1996; Rosa hybrida: Fanourakis et al., 2009; Tradescantia virginiana: Rezaei Nejad and Van Meeteren, 2005). The present study confirms those findings in rose, making clear that the leaf transpiration rate was less sensitive to decreases of RWC in high RH grown plants (Fig. 1). The possibility to reduce the negative effect of high $\mathrm{RH}$ during crop growth on stomatal functioning, and thus improving the keeping quality of ornamental plants, would be of utmost importance. Adjustments in the humidity level (e.g. breaks of moderate RH in the magnitude of days) could be a good strategy to improve the stomatal responses. However, our results have confirmed that stomatal functionality of rose leaves is determined during leaf development, and after this period the possibilities to obtain (partial) functionality for these malfunctional stomata are absent, which is in agreement with previous findings (Mortensen and Gislerød, 2000; Mortensen and Fjeld, 1995). It still remains unknown whether a moderate RH level is required throughout the complete leaf development or if a partial exposure to moderate RH during leaf development (in the scale of days) is enough to guarantee a proper stomatal functioning. In roses, some attention has been paid on the critical limit of hours with high RH per day for inducing stomatal malfunctionality (Mortensen, 2001). It has been shown that high RH for $12 \mathrm{~h}$ or more daily results in poor stomatal functioning (Mortensen, 2001). Nevertheless, regulation of RH in a scale of days is more recommended than in a scale of hours per day, since the frequent RH fluctuations promote the development of diseases, such as mildew (Mortensen and Gislerød, 2005).

In Tradescantia virginiana the loss of stomatal functionality after four days of transfer to high $\mathrm{RH}$ was related to a decrease in the leaf Abscisic Acid (ABA) concentration, and the authors speculated that a certain ABA level is required not only to induce, but also to sustain stomatal functionality (Rezaei Nejad and van Meeteren, 2008). Since our study showed that stomatal functioning in rose is independent of postdevelopment conditions, two scenarios arise: (i) leaf ABA concentration decreases after transfer to high RH, but is still above a certain threshold required for the stomatal responsivity; or (ii) the level of $\mathrm{ABA}$ after the development of stomatal apparatus (i.e. in fully developed leaves) is not important in rose. Further studies are required to clarify these hypotheses.

Our results suggest that in a rose crop grown under moderate $\mathrm{RH}$, the postdevelopment RH level will have no consequences for the keeping quality. Moreover, poor stomatal responses during the post-harvest phase can be attributed to the $\mathrm{RH}$ level during leaf development. Since the upper five leaves have been indicated as the most detrimental leaves for a proper water balance during the vase life in roses (Petersen et al., 2006), a moderate RH should be provided during the development of those leaves. Nevertheless, this could only be applied in a synchronized rose crop, as in a conventional cultivation all stages of plant development are present in the greenhouse.

\section{CONCLUSION}

Stomatal response characteristics in rose leaves are determined during leaf development, while after this period adaptation possibilities are absent. These findings lead us to the conclusion that there are no possibilities for obtaining (partial) stomatal functionality in a rose crop that has been fully grown under high $\mathrm{RH}$ and further subjected to moderate RH. However, to better understand the processes behind stomatal adaptation to high RH more detailed studies using different leaf developmental stages are needed, focusing on the adaptation ability of non fully developed leaves to a new $\mathrm{RH}$ environment.

\section{ACKNOWLEDGEMENTS}

The authors thank Foundation Alexander Onassis (Greece) and Fundação para a Ciência e a Tecnologia (Portugal) for their financial support. 


\section{Literature Cited}

Blom-Zandstra, M., Pot, C.S., Maas, F.M., Schapendonk, H.C.M. 1995. Effects of different light treatments on the nocturnal transpiration and dynamics of stomatal closure of two rose cultivars. Sci. Hort. 61:251-262.

Fanourakis, D., Tapia, A., Heuvelink, E. and Carvalho, S.M.P. 2009. Cultivar differences in the stomatal characteristics of cut roses grown at high relative humidity. Acta Hort. 847:251-258.

Gelder, A., Heuvelink, E. and Opdam, J.J.G. 2005. Tomato yield in a closed greenhouse and comparison with simulated yields in closed and conventional greenhouses. Acta Hort. 691:549-552.

Körner, O. and Challa, H. 2003. Process-based humidity control regime for greenhouse crops. Comput. Electron. Agr. 39:173-192.

Mortensen, L.M. 2001. Greenhouse climate and keeping quality of roses. Acta Hort. 543: 199-202.

Mortensen, L.M. and Gislerød, H.R. 1999. Influence of air humidity and lighting period on growth, vase life and water relations of 14 rose cultivars. Sci. Hort. 82:289-298.

Mortensen, L.M. and Gislerød, H.R. 2000. Effect of air humidity on growth, keeping quality, water relations, and nutrient content of cut roses. Gartenbauwissenschaft. 65: 40-44.

Mortensen, L.M. and Gislerød, H.R. 2005. Effect of air humidity variation on powdery mildew and keeping quality of cut roses. Sci. Hort. 104:49-55.

Mortensen, L.M., and Fjeld, T. 1995. High air humidity reduces the keeping quality of cut roses. Acta Hort. 405:148-155.

Pettersen, R.I., Mortensen, L.M., Moe, R. and Gislerød, H.R. 2006. Air humidity control essential for rose production under continuous lighting. Acta Hort. 711:323-331.

Pospisilova, J. 1996. Effect of air humidity on the development of functional stomatal apparatus. Biol. Plant. 38:197-204.

Rezaei Nejad, A. and Van Meeteren, U. 2005. Stomatal response characteristics of Tradescantia virginiana grown at high relative air humidity. Physiol. Plant. 125:324332.

Rezaei Nejad, A. and Van Meeteren, U. 2008. Dynamics of adaptation of stomatal behaviour to moderate or high relative air humidity in Tradescantia virginiana. J. Exp. Bot. 59:289-301.

Slavik, B. 1974. Methods of studying plant water relations. London: Chapman and Hall.

Torre, S. and Fjeld, T. 2001. Water loss and postharvest characteristics of cut roses grown at high or moderate relative humidity. Sci. Hort. 89:217-226.

VBN. 2001. Evaluation cards for cut flowers. VBN, Leiden, The Netherlands. 


\section{Figures}
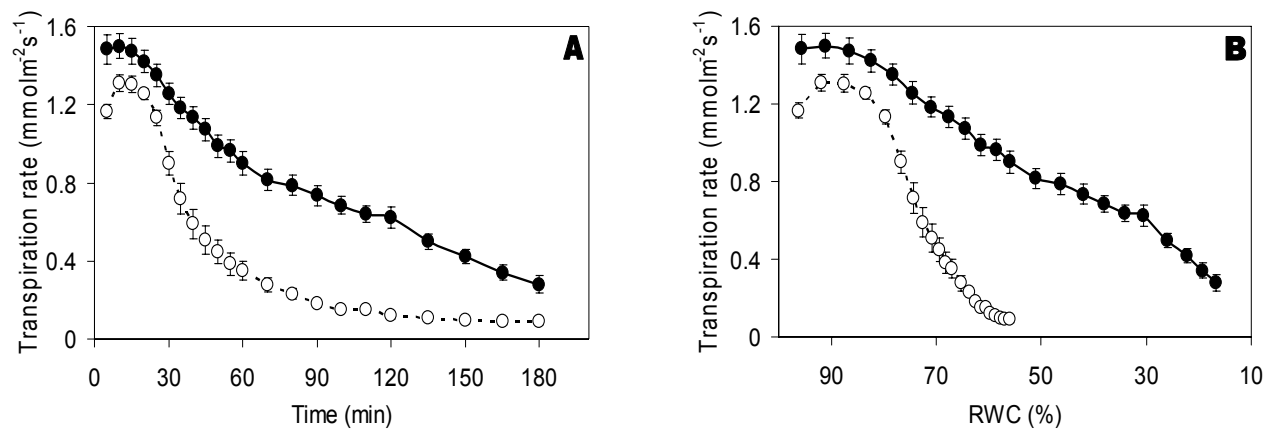

Fig. 1. Transpiration rate as a function of time (A) and as a function of relative water content (RWC) (B) during three hours of leaf desiccation in cut rose 'Prophyta', grown at moderate RH $(\mathrm{O}, 60 \%)$ and high $\mathrm{RH}(\mathbf{O}, 90 \%)$. Vertical bars indicate s.e.m. $(n=14)$.
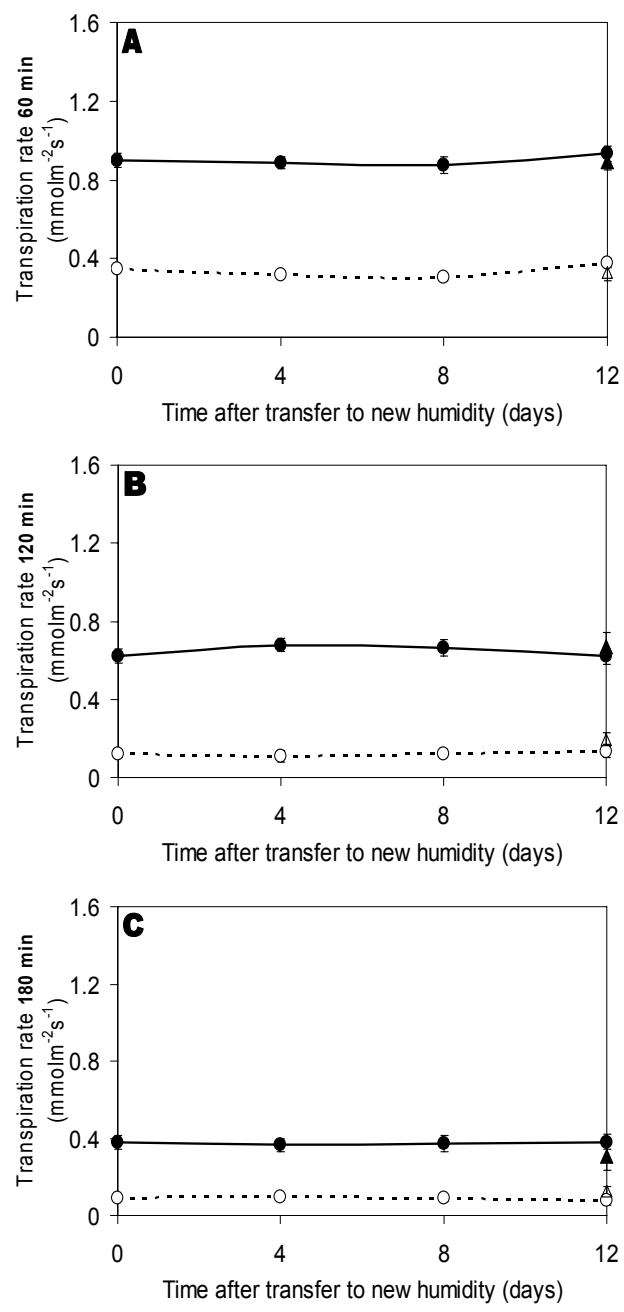

Fig. 2. Transpiration rate at different times after starting leaf desiccation (A: $60 \mathrm{~min}$; B: $120 \mathrm{~min}$; C: $180 \mathrm{~min})$ in cut rose 'Prophyta' continuously grown at moderate $(\Delta$, $60 \%)$ and at high $(\boldsymbol{\Delta}, 90 \%)$ relative humidity (control plants) as well as in plants transferred to a new humidity environment at harvest stage $(\bigcirc, 60 \% \rightarrow 90 \%$; $90 \% \rightarrow 60 \% \mathrm{RH})$ for a period up to 12 days. Vertical bars indicate s.e.m. when larger than symbols $(n=14)$. 